University of Nebraska - Lincoln

DigitalCommons@University of Nebraska - Lincoln

7-24-2009

\title{
A multiplex polymerase chain reaction assay to simultaneously distinguish Cryptosporidium species of veterinary and public health concern in cattle
}

Mónica Santín

Dante S. Zarlenga

Follow this and additional works at: https://digitalcommons.unl.edu/usdaarsfacpub

This Article is brought to you for free and open access by the U.S. Department of Agriculture: Agricultural Research Service, Lincoln, Nebraska at DigitalCommons@University of Nebraska - Lincoln. It has been accepted for inclusion in Publications from USDA-ARS / UNL Faculty by an authorized administrator of DigitalCommons@University of Nebraska - Lincoln. 


\title{
A multiplex polymerase chain reaction assay to simultaneously distinguish Cryptosporidium species of veterinary and public health concern in cattle
}

\author{
Mónica Santín ${ }^{\mathrm{a}, *}$, Dante S. Zarlenga ${ }^{\mathrm{b}}$ \\ ${ }^{a}$ Environmental Microbial and Food Safety Laboratory, Animal and Natural Resources Institute, Agricultural Research Service, \\ United States Department of Agriculture, Building 173, BARC-East, 10300 Baltimore Avenue, Beltsville, MD 20705, USA \\ ${ }^{\mathrm{b}}$ Animal Parasitic Diseases Laboratory, Animal and Natural Resources Institute, Agricultural Research Service, \\ United States Department of Agriculture, Building 1180, BARC-East, 10300 Baltimore Avenue, Beltsville, MD 20705, USA
}

\section{A R T I C L E I N F O}

\section{Article history:}

Received 10 June 2009

Received in revised form 23 July 2009

Accepted 24 July 2009

\section{Keywords:}

Cattle

Cryptosporidium

C. andersoni

C. bovis

C. parvum

C. ryanae

Multiplex

PCR

\begin{abstract}
A B S T R A C T
Four species of Cryptosporidium are routinely found in cattle: Cryptosporidium parvum, Cryptosporidium bovis, Cryptosporidium ryanae, and Cryptosporidium andersoni. It is important to determine the species of Cryptosporidium in infected cattle because $C$. parvum is the only serious pathogen for humans as well as cattle. Identification of Cryptosporidium species and genotypes currently relies on molecular methods such as polymerase chain reaction (PCR) followed by restriction fragment length polymorphism (RFLP) or gene sequencing. Incorporation of these techniques in a routine veterinary diagnostic laboratory is cost prohibitive. As such, their applications are limited primarily to research and a few public health laboratories. To overcome this problem, a multiplex PCR assay was developed for simultaneously detecting the 4 species of Cryptosporidium that commonly infect cattle. This assay specifically identifies Cryptosporidium oocysts present in cattle feces, improves the detection of mixed infections, reduces the time and cost relative to current sequencing methods, and further demonstrates the shortcomings of sequencing as the definitive method for identification when analyzing samples containing mixed infections.
\end{abstract}

Published by Elsevier B.V.

\section{Introduction}

Parasites of the genus Cryptosporidium infect humans and animals. Eight species of Cryptosporidium and one additional genotype are infectious to cattle (Santín and Trout, 2008) although only four species are found routinely; Cryptosporidium parvum, Cryptosporidium bovis, Cryptosporidium andersoni, and Cryptosporidium ryanae (previously known as the deer-like genotype) (Fayer et al., 2006, 2007, 2008; Langkjær et al., 2006; Feng et al., 2007; Brook et al., 2008; Feltus et al., 2008; Santín

\footnotetext{
* Corresponding author. Tel.: +1 301504 6774; fax: +1 3015046608 E-mail address: monica.santin-duran@ars.usda.gov (M. Santín).
}

et al., 2004, 2008). Infections with other Cryptosporidium species such as Cryptosporidium hominis (Smith et al., 2005; Park et al., 2006; Feng et al., 2007), Cryptosporidium suis and C. suis-like (Fayer et al., 2006; Geurden et al., 2006, 2007; Langkjær et al., 2006), and Cryptosporidium felis (Bornay-Llinares et al., 1999), along with the Cryptosporidium pig genotype II (Langkjær et al., 2006), have been reported only rarely. Infection with Cryptosporidium canis has been demonstrated under experimentally induced conditions (Fayer et al., 2001) but has not yet been identified in a natural setting.

A relationship exists between the age of the cattle and the species of Cryptosporidium. Most Cryptosporidium infections in pre-weaned calves are due to $C$. parvum and those in post-weaned calves are due to $C$. bovis and $C$. 
Table 1

Number of samples examined and number of samples positive using the different sets of primers.

\begin{tabular}{|c|c|c|c|c|}
\hline \multirow{2}{*}{$\begin{array}{l}\text { Cryptosporidium species/genotype } \\
\text { identified by PCR/SEQ of } \\
\text { a fragment of the SSU rDNA gene }\end{array}$} & \multirow{2}{*}{$\begin{array}{l}\text { Number of } \\
\text { samples } \\
\text { examined }\end{array}$} & \multicolumn{3}{|c|}{ Number of positive samples using different sets of primers ${ }^{a}$} \\
\hline & & $\begin{array}{l}1010 / 1011 \\
\text { (C. parvum and C. hominis) }\end{array}$ & 1005/1008 (C. bovis and C. ryanae) & $\begin{array}{l}1018 / 1019 \\
\text { (C. andersoni) }\end{array}$ \\
\hline C. parvum & 18 & 18 (C. parvum) & 0 & 0 \\
\hline C. bovis & 16 & 5 (C. parvum) & $\begin{array}{l}16 \text { ( } 15 \text { C. bovis and } 1 \text { mixed infection } \\
\text { with } C . \text { bovis/C. ryanae) }\end{array}$ & 0 \\
\hline C. ryanae & 19 & 9 (C. parvum) & $\begin{array}{l}19 \text { ( } 8 \text { C. ryanae and } 11 \text { mixed infections } \\
\text { with } C \text {. bovis/C. ryanae) }\end{array}$ & 0 \\
\hline C. andersoni & 8 & 0 & 3 (2 C. bovis and 1 C. ryanae) & 8 (C. andersoni) \\
\hline C. canis & 3 & 0 & 0 & 0 \\
\hline C. felis & 5 & 0 & 0 & 0 \\
\hline C. hominis & 3 & 3 (C. hominis) & 0 & 0 \\
\hline C. suis & 1 & 0 & 0 & 0 \\
\hline Pig genotype II & 4 & 0 & 0 & 0 \\
\hline
\end{tabular}

${ }^{\mathrm{a}}$ In parenthesis: Cryptosporidium species identified after sequencing the PCR product.

ryanae. C. andersoni is most often found in cattle over 1 year of age (Santín et al., 2004, 2008; Fayer et al., 2006, 2007; Langkjær et al., 2006; Feng et al., 2007). It is very important from a public health perspective to identify the species of Cryptosporidium present in infected cattle because of the species that commonly infect cattle, only $C$. parvum is considered zoonotic. Identification of Cryptosporidium species relies on molecular methods that include polymerase chain reaction (PCR) followed by restriction fragment length polymorphism (RFLP), or gene sequencing. Because most PCR methods that genotype Cryptosporidium make use of primers that are conserved among all Cryptosporidium species, only the dominant species in a specimen is routinely identified. Thus, infections with multiple species become difficult to diagnose and minor species frequently go undetected (Xiao and Ryan, 2008). This undermines our ability to understand the epidemiology of cryptosporidiosis in cattle.

There have been attempts to develop multiplex PCR tests for differentiating subsets of Cryptosporidium species. One such test simultaneously delineates among $C$. parvum, Cryptosporidium wrairi, Cryptosporidium baileyi and Cryptosporidium muris (Patel et al., 1999). Using this assay, $C$. parvum and $C$. wrairi generate identical fragments from the small subunit rDNA (SSU rDNA). As such, a follow-up PCR-RLFP targeting the outer wall protein (COWP) is required to distinguish among them (Patel et al., 1999). Also, a nested multiplex PCR amplifying the heat shock protein 70 was developed for detecting the 4 human Cryptosporidium species, C. parvum, C. hominis, $C$. canis, and C. felis (Lindergard et al., 2003); however, no multiplex studies have ever targeted Cryptosporidium species commonly found in cattle. Inasmuch as epidemiological studies are frequently directed at cows as a key source for human infections, a multiplex PCR test was developed to rapidly detect and accurately delineate multiple Cryptosporidium species in cattle by examining oocyst DNA. This test is based on simultaneously amplifying different sized fragments of the actin gene in the 4 most common species of Cryptosporidium found in cattle, followed by amplicon detection on agarose gels thereby eliminating the need to sequence the PCR product.

\section{Materials and methods}

\subsection{Sources of specimens, oocysts purification, and DNA extraction}

Fecal samples containing oocysts of $C$. parvum, C. bovis, C. ryanae, C. andersoni, C. hominis, C. canis, C. suis, C. felis, and the Cryptosporidium pig genotype II, as defined by sequencing PCR-amplified SSU rDNA fragments, were obtained from infected animals and humans (Table 1). Oocysts were concentrated from feces by $\mathrm{CsCl}$ centrifugation as previously described (Fayer et al., 2000; Santín et al., 2004). Total DNA was extracted from each CsClcleaned fecal sample using a modification of the DNeasy Tissue Kit (Qiagen, Valencia, California). A total of $50 \mu \mathrm{l}$ of purified oocysts were suspended in $180 \mu$ l of ATL buffer (supplied by the manufacturer) and vortexed. To this suspension, $20 \mu \mathrm{l}$ of proteinase $\mathrm{K}(20 \mathrm{mg} / \mathrm{ml})$ was added and the mixture incubated overnight at $55^{\circ} \mathrm{C}$. The next day, $200 \mu \mathrm{l}$ of $\mathrm{AL}$ buffer was added and purification proceeded as per manufacturer's instructions. The nucleic acids were eluted in $100 \mu \mathrm{l}$ of AE buffer.

\subsection{Gene amplification and sequencing}

Nucleotide sequence analyses of the SSU rDNA followed by alignment with known Cryptosporidium sequences were used to validate the identity of the oocysts. A two-step nested PCR protocol was used to amplify a fragment of the SSU rRNA gene of Cryptosporidium ( $~ 830 \mathrm{bp}$ ) using primers and PCR conditions previously described (Xiao et al., 1999; Santín et al., 2004).

To conduct the multiplex assay, a nested PCR was required. First, a single set of degenerate primers was used to amplify a fragment of the actin gene from homogeneous preparations of the 4 most common species of Cryptosporidium that infect cattle; $C$. parvum, $C$. bovis, $C$. ryanae, and $C$. andersoni. These primers (forward 5'-ATGRGWGAAGAAGWARYWCAAGC and reverse 5'-AGAARCAYTTTCTGTGKACAAT) produced a single PCR product approximately 1095 bp in length (Sulaiman et al., 2002). The primary PCR mixture contained $1 \times$ PCR buffer, $3 \mathrm{mM} \mathrm{MgCl}_{2}$, $0.2 \mathrm{mM}$ dNTP, $2.5 \mathrm{U}$ Taq (Qbiogene, Irvine, CA), $2.5 \mu \mathrm{l}$ 

C. parvum
C. andersoni
c. bovis
c. ryanae
C. parvum
c. andersoni
C. bovis
C. ryanae
C. parvum
C. andersoni
C. bovis
c. ryanae
C. parvum
C. andersoni
C. bovis
c. ryanae

C. parvum
C. andersoni
C. bovis
C. ryanae

C. parvum

C. andersoni

c. bovis

c. ryanae

C. parvum

C. andersoni

C. bovis

c. ryanae

c. parvum

C. andersoni

c. bovis

c. ryanae

C. parvum

C. andersoni

c. bovis

c. ryanae

C. parvum

C. andersoni

C. bovis

C. ryanae

C. parvum

c. andersoni

c. bovis

c. ryanae

C. parvum

C. andersoni

c. bovis

c. ryanae

C. parvum

c. andersoni

C. bovis

c. ryanae
${ }^{360}$ TGGTATGGTCAAGGCAGGTGTTGCAGGTGATGACGCTCCAAGATGTGTTTTCCCATCGATCGTTGGTCGCCCAAAAATGCCAGGT

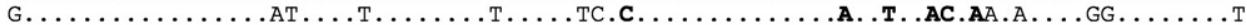

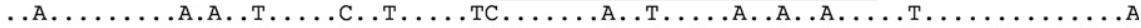
.А......... Т........

GTTATGGTAGGTATGGACCAAAAGGACTGTTATGTTGGTGATGAAGCTCAATCAAAGAGAGGTATTTTGACTTTGAAATACCCAA

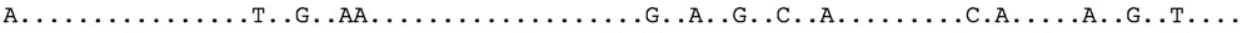

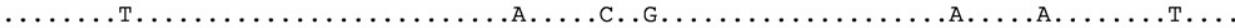

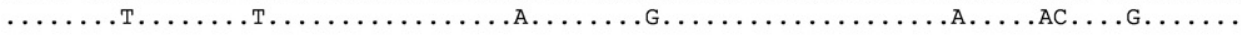
TTGAGCATGGTATTGTTACAAACTGGGAAGATATGGAGAAGATCTGGCATCATACTTTCTATAATGAATTACGTGTTGCTCCTGA

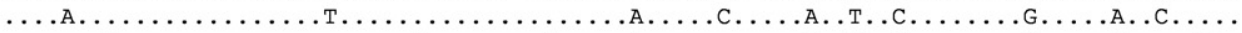

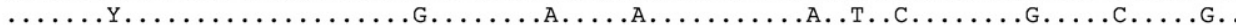

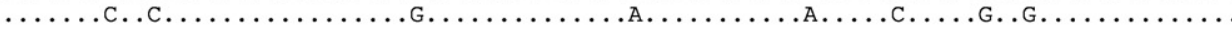
GGAACACCCAGTATTATTGACTGAAGCACCAATGAACCCAAAGGTAAATCGTGAAAGAATGACTCAAATAATGTTTGAAACATTC

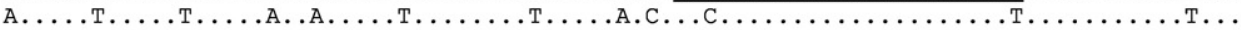

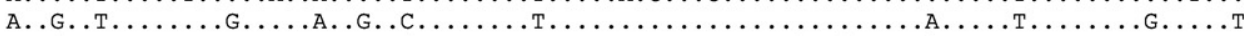

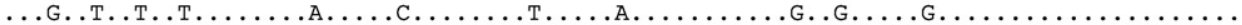

AATGTACCAGCAATGTATGTTAATATTCAGGCTGTCTTATCATTGTATGCCTCTGGTCGTACAACTGGTATTGTTTTAGATAGTG

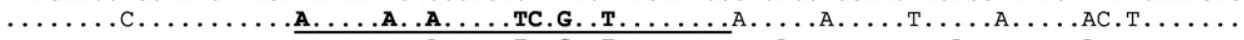

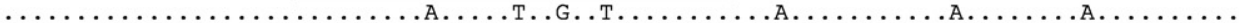

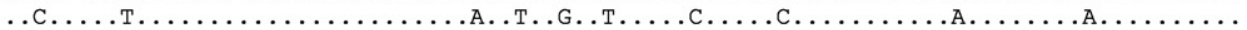

GTGATGGTGTATCACATACTGTTCCAATCTATGAAGGTTATGCTATTCCACATGCTATTATGAGATTAGATCTAGCTGGACGTGA

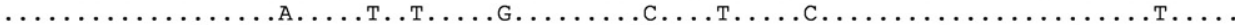

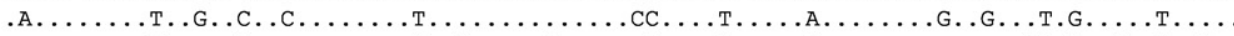

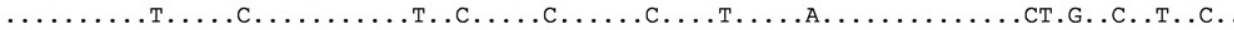

TTTAACTGATTTCTTGATGAAGATTCTCCACGACCGTGGTTACAGCTTTACAACAACAGCTGAGAGAGAAATCGTAAGAGATATT

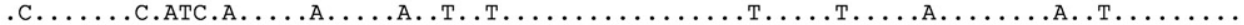

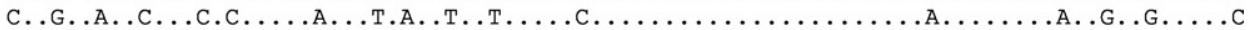

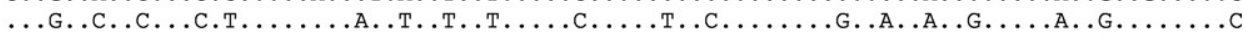

AAGGAAAAGCTCTGCTACATTGCTTTAGATTACGAGGAAGAAATGAAGAAATCTCAAGAATCTTCTGAATTAGAGAAGACATATG

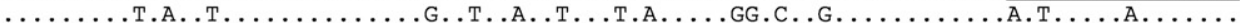

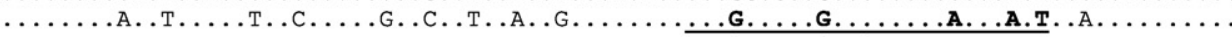

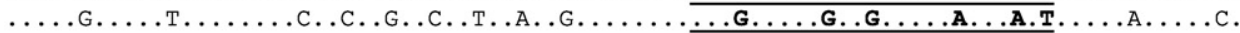

AACTACCAGATGGCCATGTAATTACTGTAGGTAGTGAAAGATTCAGATGTCCTGAGGCTTTATTCCAACCAGGTTTTTTAGGTAA

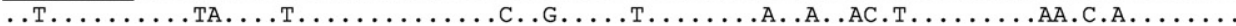
.T... $\ldots$. . .................................................

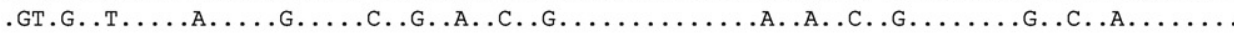
AGAAGCTGTCGGTATTGGTGAAACTACATTCCAATCTATCATGAAATGTGATCTTGATATCCGTAAAGACCTTTATGCCAATATT

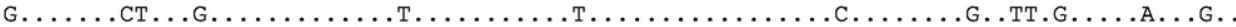

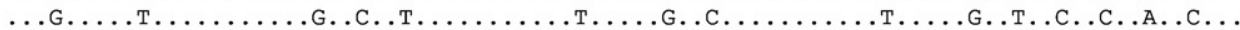

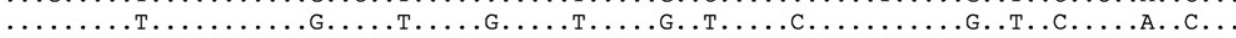

GTTTTATCTGGAGGTACAACAATGTATCCAGGTATTGGAGAAAGAATGACAAAAGAGCTCACTTCTTTGGCTCCATCAACAATGA

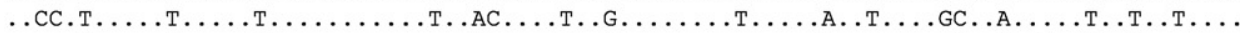

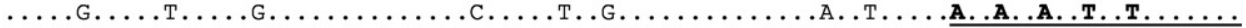

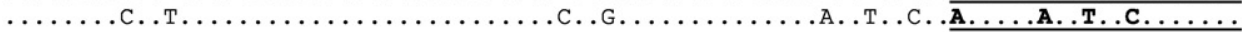
AGATCAAGGTTGTTGCACCTCCTGAGCGTAAATACTCTGTATGGATTGGTGGTTCCATCTTATCTTCTTTATCTACTTTCCAACA

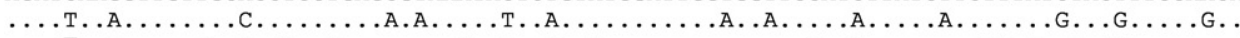

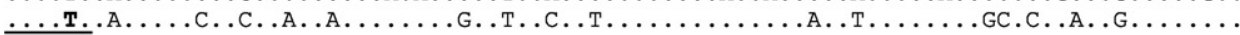

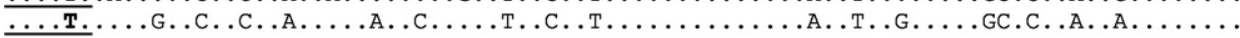

AATGTGGATCACTAAGGAAGAG ${ }^{1407}$

G.......T.........A

....................

$\ldots \ldots \ldots \ldots$

Fig. 1. Locations of primers used for nested multiplex PCR. Sequences above are derived from the following accession numbers: M86241 (C. parvum), AF382352 (C. andersoni), AY741307 (C. bovis), and EU410345 (C. ryanae). Nucleotide numbering is based upon the complete nucleotide sequence of the $C$. parvum actin gene. Locations of the forward and reverse primers corresponding to each species are underlined and highlighted in bold. Primer sets were defined as 1010/1011 (C. parvum and C. hominis); 1005/1008 (C. bovis and C. ryanae) and; 1018/1019 (C. andersoni). The first bold primer for each species is designated as the forward primer, and all reverse primers are the reverse complement of those shown above. "Dots" indicate conserved nucleotides based upon the C. parvum sequence. First round PCR was performed with forward and reverse degenerate primers as defined in Section 2. These primers bind at positions 322 and 1429, respectively, and are not shown in the sequence above. 
BSA $(0.1 \mathrm{~g} / 10 \mathrm{ml}), 1 \mu \mathrm{M}$ of each primer, and $5 \mu \mathrm{l}$ of the template DNA in a $50 \mu \mathrm{l}$ reaction. A total of 35 cycles, each consisting of $94{ }^{\circ} \mathrm{C}$ for $45 \mathrm{~s}, 50^{\circ} \mathrm{C}$ for $45 \mathrm{~s}$, and $72{ }^{\circ} \mathrm{C}$ for $1 \mathrm{~min}$, was performed; an initial pre-heat step at $94^{\circ} \mathrm{C}$ for $5 \mathrm{~min}$ and a final extension step at $72{ }^{\circ} \mathrm{C}$ for $10 \mathrm{~min}$ were also included.

For the nested PCR, three sets of specific primers were designed based upon multiple sequence alignment of the actin genes from each species. The locations of the primers used for the multiplex are shown in Fig. 1; the first primer set 1010 (5'-AATCGTGAAAGAATGACTCAAATA) 1011 (5'CTGGTAGTTCATATGTCTTCTCTAA) amplifies a $400 \mathrm{bp}$ fragment from $C$. parvum; and the second primer set 1018 (5'GCTGTGTTTTCCCATCAATTGTACGA) and 1019 (5'-GCATACAAAGACAGAACAGCTTGTATATTT) amplifies a $350 \mathrm{bp}$ fragment of $C$. andersoni; and the third primer set 1005 (5'-GAAGTCTCAGGAATCTTCAGAAATT) and 1008 (5'TAATCTTCATTGTAGAAGGTGCTTAT) amplifies a $300 \mathrm{bp}$ fragment from both $C$. bovis and $C$. ryanae; The third base (bold) from the $3^{\prime}$ end of primer 1008 was deliberately changed from " $A$ " to " $T$ " to destabilize non-specific primer binding to DNA from species other than $C$. bovis and $C$. ryanae. The nested PCR mixture contained $1 \times$ PCR buffer, $1.5 \mathrm{mM} \mathrm{MgCl}$, $0.2 \mathrm{mM}$ dNTP, $2.5 \mathrm{U}$ Taq (Qbiogene, Irvine, CA), $2.5 \mu \mathrm{l} \mathrm{BSA}(0.1 \mathrm{~g} / 10 \mathrm{ml}), 1 \mu \mathrm{M}$ of each primer, and $2 \mu \mathrm{l}$ of the primary PCR reaction in a $50 \mu \mathrm{l}$ reaction. A total of 40 cycles, each consisting of $95^{\circ} \mathrm{C}$ for $30 \mathrm{~s}, 60^{\circ} \mathrm{C}$ for $30 \mathrm{~s}$, and $72{ }^{\circ} \mathrm{C}$ for $2 \mathrm{~min}$, was performed; an initial pre-heat step at $95{ }^{\circ} \mathrm{C}$ for $2 \mathrm{~min}$ and a final extension step at $72{ }^{\circ} \mathrm{C}$ for $7 \mathrm{~min}$ were also included.

PCR products were separated on $2 \%$ NuSieve GTC agarose gels (FMC BioProducts, Rockland, ME) and visualized after ethidium bromide staining. All PCR products were purified using Exo-SAP-IT ${ }^{\mathrm{TM}}$ (USB Corporation, Cleveland, $\mathrm{OH}$ ), and sequenced in both directions on an ABI3100 Genetic Analyzer (Applied Biosystems, Foster City, CA) using the actin nested PCR primers and Big Dye $\mathrm{P}^{\mathrm{TM}}$ Terminator v3.1 chemistries (Applied Biosystems, Foster City, CA). Sequence chromatograms of each strand were aligned and examined with Lasergene software (DNASTAR, Inc., Madison, WI).

\subsection{Experimental design}

The amplification specificities of the PCR primers putatively identified as species specific were validated on DNAs from known homogeneous samples of C. parvum, C. bovis/C. ryanae, and C. andersoni both individually and in all possible DNA combinations to mimic naturally derived samples. The specificity of the primers was validated by sequencing all PCR amplicons generated during the experiment to corroborate that the correct Cryptosporidium species was being amplified and that no non-specific amplification was taking place (data not shown). Comparable amounts of DNA from each species were included in all mixtures prior to diluting to $6 \mu$ l. Concentrations of DNA could not be spectrophotometrically quantitated for parasite material because of host and environmental DNAs which routinely contaminate the samples. As such, PCR using parasite-conserved rDNA primers was used to normalize the amounts of each parasite DNA prior to mixing. To normalize the DNA concentrations, serial dilutions of DNA from each species were PCR amplified under identical conditions where the chosen cycle number was within the linear range of the amplification curve for all dilutions. PCR products were separated by agarose gel electrophoresis and stained with ethidium bromide. The gels were scanned and band signal intensities compared. Stock DNA samples were diluted to approximate the same DNA level in each sample (species). The above experiment was then repeated after the DNAs were diluted to validate the normalized stock DNA samples. DNA trial samples were prepared as follow: samples 1-3 contained $2 \mu \mathrm{l}$ of $C$. parvum, $C$. bovis, and $C$. andersoni, respectively, plus $4 \mu \mathrm{l}$ of $\mathrm{dH}_{2} \mathrm{O}$ to obtain a final volume of $6 \mu \mathrm{l}$; sample 4 contained $2 \mu$ l each of $C$. parvum and $C$. bovis, plus $2 \mu$ l of water to obtain a final volume of $6 \mu \mathrm{l}$; sample 5 contained $2 \mu \mathrm{l}$ each of $C$. parvum and $C$. andersoni, plus $2 \mu$ l of water to; sample 6 contained $2 \mu \mathrm{l}$ each of $C$. bovis and $C$. andersoni, plus $2 \mu \mathrm{l}$ of water to obtain a final volume of $6 \mu \mathrm{l}$; and sample 7 contained $2 \mu$ l each of $C$. parvum, $C$. bovis, and $C$. andersoni to obtain a final volume of $6 \mu \mathrm{l}$. All $6 \mu \mathrm{l}$ samples were subjected to the primary PCR followed by the nested multiplex PCR.

Once validated on control samples, the PCR assay was used to examine 61 DNA samples obtained from naturally infected cattle. The results obtained directly from agarose gels and from sequencing each band of the multiplex PCR were compared to infection data obtained by benchmark sequencing the SSU rDNA of each environmentally derived sample followed by alignment with published sequences (Table 1). In addition, 16 samples containing DNA from 4 other Cryptosporidium species (C. canis, $C$. felis, $C$. hominis, $C$. suis) and one genotype (pig genotype II) not routinely found in cattle were tested to validate primer specificity (Table 1).

To determine the sensitivity of the methods used to detect Cryptosporidium oocysts in the present study, Cryptosporidium negative bovine feces were obtained. Six replicate $15 \mathrm{~g}$ fecal specimens were each spiked with oocysts of $C$. parvum at the rate of 10,100 , and 1000 oocysts/g and subjected to the same methods of concentration and molecular detection as described above.

\section{Results}

In controlled experiments, normalized amounts of DNA from each species were mixed in all possible combinations to validate the multiplex test and the choice of primers (Fig. 1). The expected size amplicons were generated from each pure Cryptosporidium species DNA (lanes 1-3) as well as all possible combinations of these DNAs (lanes 4-7) (Fig. 2). No primer cross-reactivity was observed among the cattle species tested.

In the 61 DNA samples obtained from naturally infected cattle, the targeted amplicons for all 4 cattle species ( $C$. parvum, $C$. andersoni, $C$. bovis, or $C$. ryanae) were observed and in various combinations. The presence of $C$. parvum and $C$. andersoni resulted in amplicon sizes of 400 bp and $350 \mathrm{bp}$, respectively. The presence of $C$. bovis or $C$. ryanae resulted in a single amplicon of $300 \mathrm{bp}$. Also, an amplicon of $400 \mathrm{bp}$ was obtained when the $C$. parvum primer set 


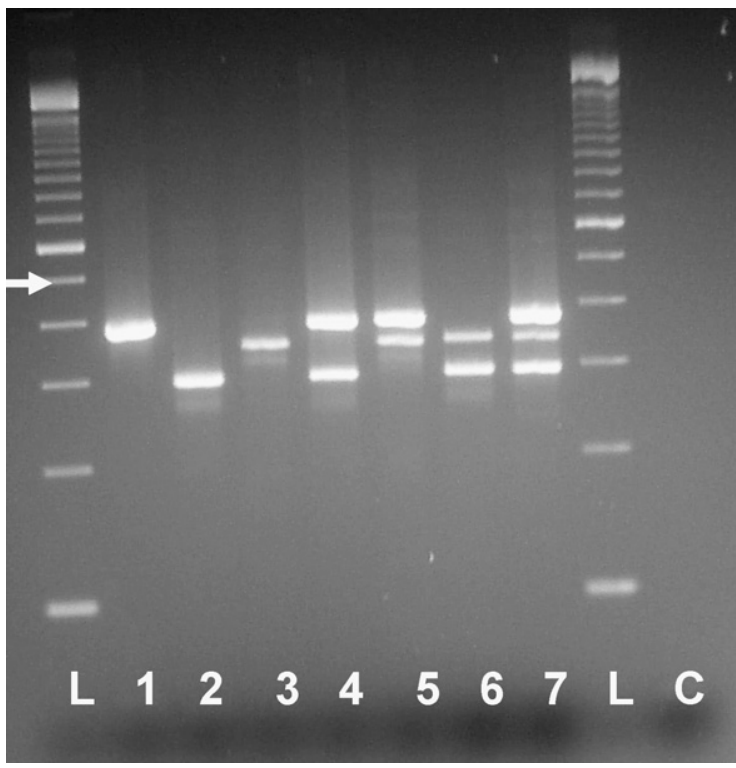

Fig. 2. Multiplex PCR amplification of C. parvum, C. bovis, and C. andersoni observed on $2 \%$ agarose gels stained with ethidium bromide. Lane L, 100bp DNA ladder; lane 1, C. parvum; lane 2, C. bovis; lane 3, C. andersoni; lane $4, C$. parvum and C. bovis; lane $5, C$. parvum and $C$. andersoni; lane $6, C$. bovis and $C$. andersoni; lane 7, C. parvum, C. bovis, and C. andersoni; lane C, negative control. The white arrow indicates the $500 \mathrm{bp}$ marker of the 100 bp DNA ladder.

1010/1011 was used to amplify 3 DNA samples identified previously as $C$. hominis by SSU rDNA sequencing. All 3 primer sets failed to amplify DNA from C. canis, $C$. felis, $C$. suis, and the Cryptosporidium pig genotype II.

All PCR products were sequenced for confirmation. In every case, the Cryptosporidium species identified by the multiplex PCR assay corresponded with the species defined by SSU rRNA gene sequencing; however, the multiplex PCR also identified mixed infections of $C$. parvum/C. bovis, C. parvum/C. ryanae, C. andersoni/C. bovis, and $C$. andersoni/C. ryanae in $5,9,2$, and 1 of the samples examined, respectively (Table 1 ). These mixed infections were missed by SSU rDNA sequencing (Table 1 ). Furthermore, the 12 mixed infections containing both $C$. bovis and $C$. ryanae were confirmed by multiple peaks in key locations in the sequence chromatograms (i.e., the presence of two nucleotides at the same position) of the actin gene fragment (data not shown).

Of the 6 fecal specimens each spiked at 10,100, and 1000 C. parvum oocysts per gram, 66\%, 100\%, and $100 \%$ were found positive by the multiplex PCR, respectively (data not shown).

\section{Discussion}

For identification of Cryptosporidium species and genotypes, SSU rRNA gene sequencing is the most commonly used method. This technique as well as PCRRFLP are very sensitive and can detect a wide range of Cryptosporidium species and genotypes (Xiao and Ryan, 2008); however, these methods have not been found useful in detecting mixed infections because the dominant species or genotype in the specimen becomes preferentially amplified by the PCR when only genus-specific primers are used (Cama et al., 2006). To develop the multiplex PCR assay, the actin gene was targeted because it provided more sequence variation for primer design.

The multiplex PCR assay developed herein generated the predicted 3 different sized amplicons for $C$. parvum, $C$. andersoni, and $C$. bovis/C. ryanae thereby identifying the most common species of Cryptosporidium that infect cattle. Furthermore, the multiplex PCR assay was able to detect mixed infections that were missed by conventional sequencing of the SSU rRNA gene. Preliminary data on assay sensitivity suggest that DNA extracted from 10 oocysts in feces was insufficient to generate consistent detection. However, 100 oocysts in feces reproducibly gave positive results by multiplex PCR. Detection efficiency in the range of 10-100 oocysts was not determined. These data confirm the results of others advocating the inadequacies of sequencing only (Cama et al., 2006), and suggest that mixed infections in cattle may be more prevalent than originally believed.

It is crucial to differentiate among Cryptosporidium species infecting cattle because only $C$. parvum is zoonotic where $C$. bovis, $C$. andersoni, and $C$. ryanae are cattle adapted (Lindsay et al., 2000; Fayer et al., 2005, 2008; Santín and Trout, 2008). Results presented here indicate that 44\% (14/ 32 ) of the $C$. parvum-infected animals were missed by conventional SSU rDNA sequencing. Thus, the multiplex PCR is a better method for differentiating between zoonotic and non-zoonotic species of Cryptosporidium of cattle and is critical for determining the risk to public health. Furthermore, the amplification of $C$. hominis using the $C$. parvum primer set 1010/1011 can be considered an added advantage because the presence of the $400 \mathrm{bp}$ amplicon will indicate that one of the two most common species responsible for human cryptosporidiosis, C. parvum and $C$. hominis, is present in a particular sample.

With regard to animal health, C. parvum infection causes diarrhea in young calves (Fayer et al., 1998; de Graaf et al., 1999) and C. andersoni infection causes reduced milk production in mature cows (Esteban and Anderson, 1995); however, neither disease nor changes in host physiology have been linked to animals infected with $C$. bovis or $C$. ryanae (Fayer et al., 2005, 2008). As such, there is no practical need to differentiate between these species at this time. In conclusion, the advantages of the multiplex PCR test described in this study are its ability to: (1) identify mixed infections which are critical to understanding cryptosporidiosis epidemiology; (2) differentiate the zoonotic pathogen $C$. parvum from the other 3 common species of Cryptosporidium in cattle without further analysis, and; (3) identify the presence of $C$. parvum as a minor component of Cryptosporidium-infected animals that is often missed using conventional sequencing methodologies.

\section{References}

Bornay-Llinares, F.J., da Silva, A.J., Moura, I.N.S., Myjak, P., Pietkiewicz, H., Kruminis-Lozowska, W., Graczyk, T.K., Pieniazek, N.J., 1999. Identification of Cryptosporidium felis in a cow by morphologic and molecular methods. Appl. Environ. Microbiol. 65, 1455-1458. 
Brook, E.J., Hart, C.A., French, N.P., Christley, R.M., 2008. Prevalence and risk factors for Cryptosporidium spp. infection in young calves. Vet. Parasitol. 152, 46-52.

Cama, V., Gilman, R.H., Vivar, A., Ticona, E., Ortega, Y., Bern, C., Xiao, L., 2006. Mixed Cryptosporidium infections and HIV. Emerg. Infect. Dis. $12,1025-1028$.

de Graaf, D.C., Vanopdenbosch, E., Ortega-Mora, L.M., Abbassi, H., Peeters, J.E., 1999. A review of the importance of cryptosporidiosis in farm animals. Int. J. Parasitol. 29, 1269-1287.

Esteban, E., Anderson, B.C., 1995. Cryptosporidium muris: prevalence, persistency, and detrimental effect on milk production in a dry lot dairy. J. Dairy Sci. 78, 1068-1072.

Fayer, R., Gasbarre, L., Pasquali, P., Canals, A., Almeria, S., Zarlenga, D., 1998. Cryptosporidium parvum infection in bovine neonates: dynamic clinical, parasitic and immunologic patterns. Int. J. Parasitol. 28, 4956.

Fayer, R., Santín, M., Trout, J.M., 2007. Prevalence of Cryptosporidium species and genotypes in mature dairy cattle on farms in eastern United States compared with younger cattle from the same locations. Vet. Parasitol. 145, 260-266.

Fayer, R., Santín, M., Trout, J.M., 2008. Cryptosporidium ryanae n. sp. (Apicomplexa: Cryptosporidiidae) in cattle (Bos taurus). Vet. Parasitol. 156, 191-198.

Fayer, R., Santín, M., Trout, J.M., Greiner, E., 2006. Prevalence of species and genotypes of Cryptosporidium found in 1-2-year-old dairy cattle in the eastern United States. Vet. Parasitol. 135, 105-112.

Fayer, R., Santín, M., Xiao, L., 2005. Cryptosporidium bovis n. sp. (Apicomplexa: Cryptosporidiidae) in cattle (Bos taurus). J. Parasitol. 91, 624629.

Fayer, R., Trout, J.M., Craczyk, T.D., Lewis, E.J., 2000. Prevalence of Cryptosporidium, Giardia, and Eimeria infections in post-weaned and adult cattle on three Maryland farms. Vet. Parasitol. 93, 103-112.

Fayer, R., Trout, J.M., Xiao, L., Morgan, U.M., Lai, A.A., Dubey, J.P., 2001. Cryptosporidium canis $n$. sp. from domestic dogs. J. Parasitol. 87, 14151422.

Feltus, D.C., Giddings, C.W., Khaitsa, M.L., McEvoy, J.M., 2008. High prevalence of Cryptosporidium bovis and the deer-like genotype in calves compared to mature cows in beef cow-calf operations. Vet. Parasitol. $151,191-195$

Feng, Y., Ortega, Y., He, G., Das, P., Xu, M., Zhang X., Fayer, R., Gatei, W., Cama, V., Xiao, L., 2007. Wide geographic distribution of Cryptosporidium bovis and the deer-like genotype in bovines. Vet. Parasitol. 144, $1-9$.

Geurden, T., Berkvens, D., Martens, C., Casaert, S., Vercruysse, J., Claerebout, E., 2007. Molecular epidemiology with subtype analysis of Cryptosporidium in calves in Belgium. Parasitology 134, 19811987.
Geurden, T., Goma, F.Y., Siwila, J., Phiri, I.G., Mwanza, A.M., Gabriel, S., Claerebout, E., Vercruysse, J., 2006. Prevalence and genotyping of Cryptosporidium in three cattle husbandry systems in Zambia. Vet. Parasitol. 138, 217-222.

Langkjær, R.B., Vigre, H., Enemark, H.L., Maddox-Hyttel, C., 2006. Molecular and phylogenetic characterization of Cryptosporidium and Giardia from pigs and cattle in Demark. Parasitology 134, 339-350.

Lindergard, G., Nydam, D.V., Wade, S.E., Schaaf, S.L., Mohammed, H.O. 2003. A novel multiplex polymerase chain reaction approach for detection of four human infective Cryptosporidium isolates: Cryptosporidium parvum, types $\mathrm{H}$ and $\mathrm{C}$, Cryptosporidium canis, and Cryptosporidium felis in fecal and soil samples. J. Vet. Diagn. Invest. 15, 262267.

Lindsay, D.S., Upton, S.J., Owens, D.S., Morgan, U.M., Mead, J.R., Blagburn, B.L., 2000. Cryptosporidium andersoni n. sp. (Apicomplexa: Cryptosporiidae) from cattle, Bos Taurus. J. Eukaryot. Microbiol. 47, 91-95.

Park, J.H., Guk, S.M., Han, E.T., Shin, E.H., Kim, J.L., Chai, J.Y., 2006. Genotype analysis of Cryptosporidium spp. prevalent in a rural village in Hwasun-gun, Republic of Korea. Korean J. Parasitol. 44, 27-33.

Patel, S., Pedraza-Díaz, S., McLauchlin, J., 1999. The identification of Cryptosporidium species and Cryptosporidium parvum directly from whole faeces by analysis of a multiplex PCR of the 18S rRNA gene and by PCR/RFLP of the Cryptosporidium outer wall protein (COWP) gene. Int. J. Parasitol. 29, 1241-1247.

Santín, M., Trout, J.M., 2008. Livestock. In: Fayer, R., Xiao, L. (Eds.), Cryptosporidium and Cryptosporidiosis. 2nd ed. CRC Press, Boca Raton, FL, pp. 451-483.

Santín, M., Trout, J.M., Fayer, R., 2008. A longitudinal study of cryptosporidiosis in dairy cattle from birth to 2 years of age. Vet. Parasitol. 155, $15-23$.

Santín, M., Trout, J.M., Xiao, L., Zhou, L., Greiner, E., Fayer, R., 2004. Prevalence and age-related variation of Cryptosporidium species and genotypes in dairy calves. Vet. Parasitol. 122, 103-117.

Smith, H.V., Nichols, R.A.B., Mallon, M., Macleod, A., Tait, A., Reilly, W.J., Browning, L.M., Gray, D., Reid, S.W., Wastling, J.M., 2005. Natural Cryptosporidium hominis infections in Scottish cattle. Vet. Rec. 156, 710-711.

Sulaiman, I.M., Lai, A.A., Xiao, L., 2002. Molecular phylogeny and evolutionary relationships of Cryptosporidium parasited at the actin locus. J. Parasitol. 88, 388-394.

Xiao, L., Escalante, L., Yang, C., Sulaiman, I., Escalante, A.A., Montali, R.J., Fayer, R., Lal, A.A., 1999. Phylogenetic analysis of Cryptosporidium parasites based on the small-subunit rRNA gene locus. Appl. Environ. Microbiol. 65, 578-1583.

Xiao, L., Ryan, U.M., 2008. Molecular epidemiology. In: Fayer, R., Xiao, L. (Eds.), Cryptosporidium and Cryptosporidiosis. 2nd ed. CRC Press, Boca Raton, FL, pp. 119-171. 